\title{
Deleterious RAD51 Gene Mutation
}

National Cancer Institute

\section{Source}

National Cancer Institute. Deleterious RAD51 Gene Mutation. NCI Thesaurus. Code

C156011.

A change in the nucleotide sequence of the RAD51 gene that is associated with increased risk of disease. 